\title{
Amitriptyline-induced ventricular tachycardia: a case report
}

\author{
Khandker Mohammad Nurus Sabah', Abdul Wadud Chowdhury' ${ }^{1}$ Mohammad Shahidul Islam²*, \\ Bishnu Pada Saha', Syed Rezwan Kabir ${ }^{1}$ and Shamima Kawser ${ }^{3}$
}

\begin{abstract}
Background: In Bangladesh, each emergency physician faces amitriptyline overdose nearly a day. An acute cardiovascular complication, one of the worst complications is mainly responsible for the mortality in tricyclic overdose. Recently, we managed ventricular tachycardia in a young female presented with an impaired consciousness $10 \mathrm{~h}$ after intentionally ingesting $2500 \mathrm{mg}$ amitriptyline. Here, we report it, discuss how the electrocardiography is vital to acknowledge and predict it and its' complications and also the recent update of the management of it.
\end{abstract}

Case presentation: A young married Bangladeshi-Bengali girl, 25-year-old, having a history of disharmony with her husband, came with an impaired consciousness after intentionally ingesting $2500 \mathrm{mg}$ amitriptyline about $10 \mathrm{~h}$ before arrival. There was blood pressure 140/80 $\mathrm{mmHg}$, heart rate 140 beats-per-min, temperature $103^{\circ} \mathrm{F}$, Glasgow coma scale 10/15, wide complex tachycardia with QRS duration of $178 \mathrm{~ms}$ in electrocardiography, blood pH 7.36. Initially, treated with $100 \mathrm{ml} 8.4 \%$ sodium bicarbonate. After that, QRS duration came to $100 \mathrm{~ms}$ in electrocardiography within 10 min of infusion. To maintain the pH 7.50-7.55 over the next $24 \mathrm{~h}$, the infusion of $8.4 \%$ sodium bicarbonate consisting of $125 \mathrm{ml}$ dissolved in $375 \mathrm{ml}$ normal saline was started and titrated according to the arterial blood gas analysis. Hence, a total dose of $600 \mathrm{mmol}$ sodium bicarbonate was given over next $24 \mathrm{~h}$. In addition to this, gave a $500 \mathrm{ml}$ intravenous lipid emulsion over $2 \mathrm{~h}$ after $24 \mathrm{~h}$ of admission as she did not regain her consciousness completely. Afterward, she became conscious, though, in electrocardiography, ST/T wave abnormality persisted. So that, we tapered sodium bicarbonate infusion slowly and stopped it later. At the time of discharge, she was by heart rate 124/min, QRS duration $90 \mathrm{~ms}$ in electrocardiogram along with other normal vital signs.

Conclusion: Diagnosis of amitriptyline-induced ventricular tachycardia is difficult when there is no history of an overdose obtained. Nevertheless, it should be performed in the clinical background and classic electrocardiographic changes and wise utilization of sodium bicarbonate, intravenous lipid emulsion, and anti-arrhythmic drugs may save a life.

Keywords: Tricyclic antidepressants, Amitriptyline overdoses, Amitriptyline-induced ventricular tachycardia, Wide complex tachycardia

\section{Background}

In Bangladesh, amitriptyline is the commonly used drug as an anti-depressant and overdose cases are faced almost daily in our practical life, though there are no accurate data regarding the incidence and prevalence of it. Worldwide, tricyclic antidepressants (TCA) are identified as

\footnotetext{
*Correspondence: shahid.hf09@gmail.com

2 Anwer Khan Modern Medical College Hospital, Road-08, Dhanmondi, Dhaka 1209, Bangladesh

Full list of author information is available at the end of the article
}

one of the most frequently ingested substances in selfpoisoning hitherto after being first reported in 1959 [1]. Among them, amitriptyline is one of the toxic tricyclic antidepressant [2-5]. Fatal dysrhythmias are rare as ventricular tachycardia occurs to only approximately $4 \%$ of all cases [6, 7]. Here, we report a case of amitriptylineinduced ventricular tachycardia (AIVT) and discuss the importance of electrocardiography (ECG) in this case and the recent update of overall management of it. 


\section{Case presentation \\ Case}

A 25-year-old young married Bangladeshi-Bengali female was brought to the emergency department by her relatives with the presentation of an impaired level of consciousness after intentionally ingesting $100 \times 25 \mathrm{mg}$ (2500 $\mathrm{mg}$ total) tablets of amitriptyline approximately $10 \mathrm{~h}$ prior to arrival. There was no suicide note written but found 10 empty strips, each containing 10 tablets that indicated the patient had taken 100 tablets of $25 \mathrm{mg}$ amitriptyline. She had a history of disharmony with her husband. 2 years backward, she incised her left forearm by blade deliberately.

At the emergency, blood pressure was $140 / 80 \mathrm{mmHg}$, heart rate 140 beats-per-min, respiratory rate 24 breaths/ min with oxygen saturation $95 \%$ on room air, temperature $103^{\circ} \mathrm{F}$, Glasgow coma scale $10 / 15$ as she opened his eyes to verbal response, localized painful stimuli and spoke inappropriate words (E2, M5, V3). Abdominal examination revealed distended urinary bladder. There was no lateralizing sign in the neurological examination. ECG revealed wide complex tachycardia (Fig. 1) with QRS duration $178 \mathrm{~ms}$. Blood $\mathrm{pH}$ was 7.36. She immediately transferred to a cardiac coronary unit (CCU) for monitoring and management purpose, where she was treated initially with $100 \mathrm{ml} 8.4 \%$ sodium bicarbonates in an undiluted state given intravenously over $5 \mathrm{~min}$. Heart rate back to 115 beats-per-min within $10 \mathrm{~min}$ after infusion of sodium bicarbonate. In the limb leads, QRS duration came to $100 \mathrm{~ms}$ and in chest leads, ST/T wave changes were seen on ECG (Fig. 2). Over the next $24 \mathrm{~h}$, sodium bicarbonate infusion consisting of $125 \mathrm{ml}$ dissolved in $375 \mathrm{ml}$ normal saline was started and titrated according to the report of arterial blood gas analysis done $6 \mathrm{~h}$ to maintain the $\mathrm{pH} 7.5-7.55$. Initially, sodium bicarbonate infusion started at a rate of $100 \mathrm{ml} / \mathrm{h}$. A total dose of $600 \mathrm{mmol}$ sodium bicarbonate was required in $24 \mathrm{~h}$. Other investigations-serum electrolyte, random blood sugar was normal. On Day 2, as she did not regain his consciousness, intravenous lipid emulsion $500 \mathrm{ml}$ was given over $2 \mathrm{~h}$ after $24 \mathrm{~h}$ of admission. Afterward that, she regained her consciousness completely. Sodium bicarbonate infusion was tapered slowly and stopped it later. Her serum electrolytes done at the end of Day 2 were also normal. In ECG, ST/T wave abnormality persisted (Fig. 3). On Day 3, she was transferred to post-CCU and

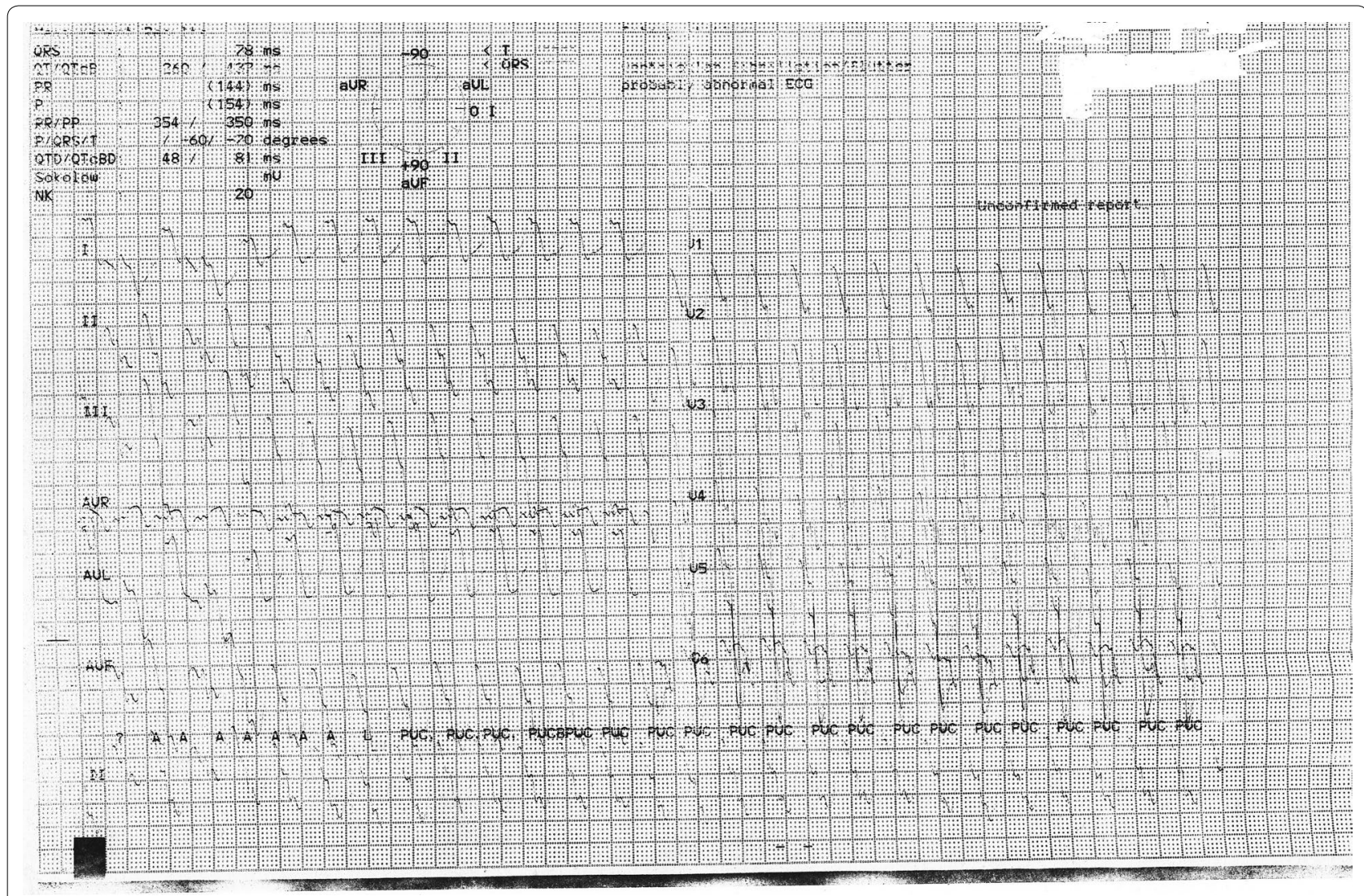

Fig. 1 Ventricular tachycardia following intentional ingestion of $2500 \mathrm{mg}$ amitriptyline in a female patient on admission 


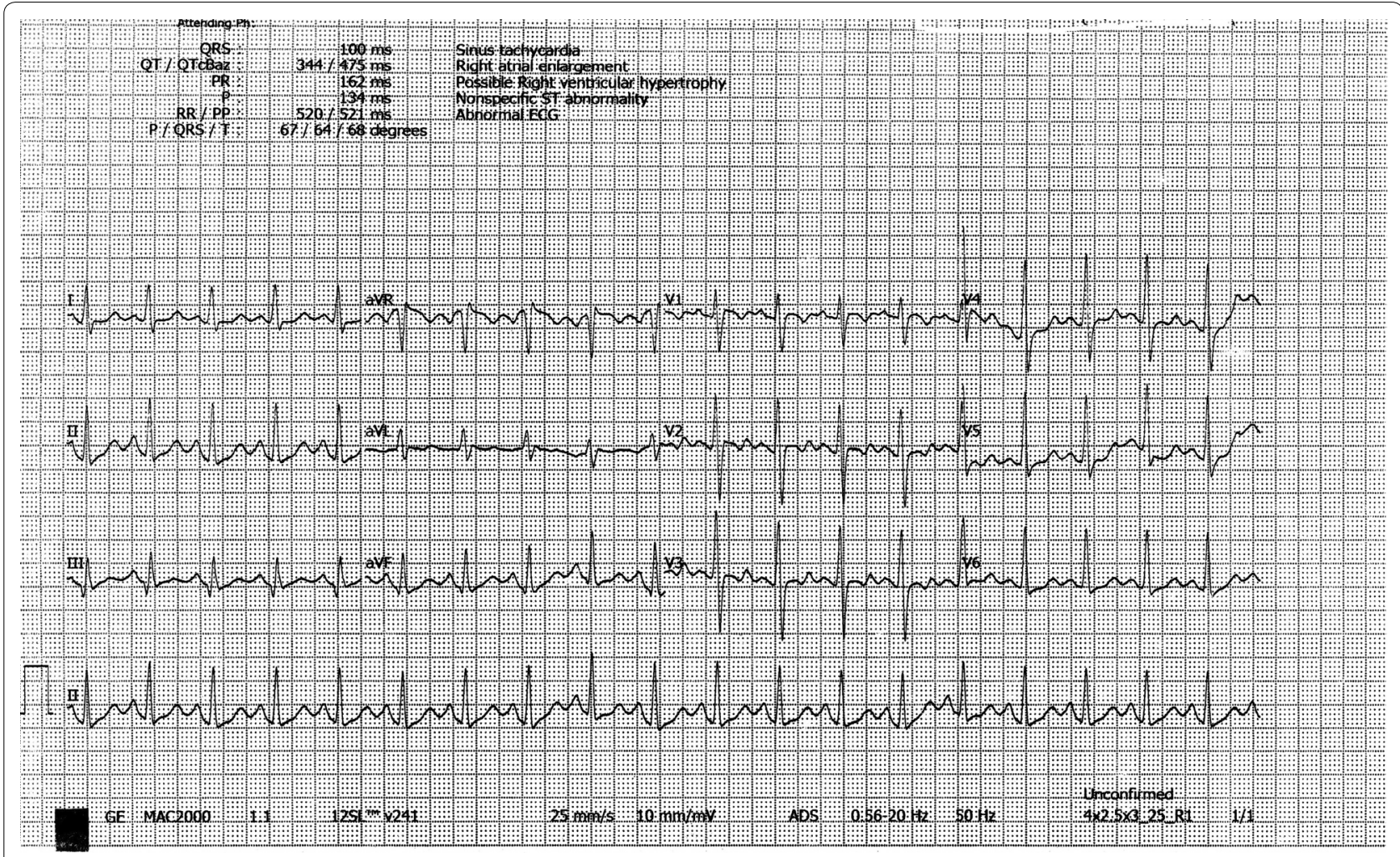

Fig. 2 Sinus tachycardia after giving $\mathrm{NaHCO}_{3}$ with QRS duration 100 ms and ST/T wave abnormality

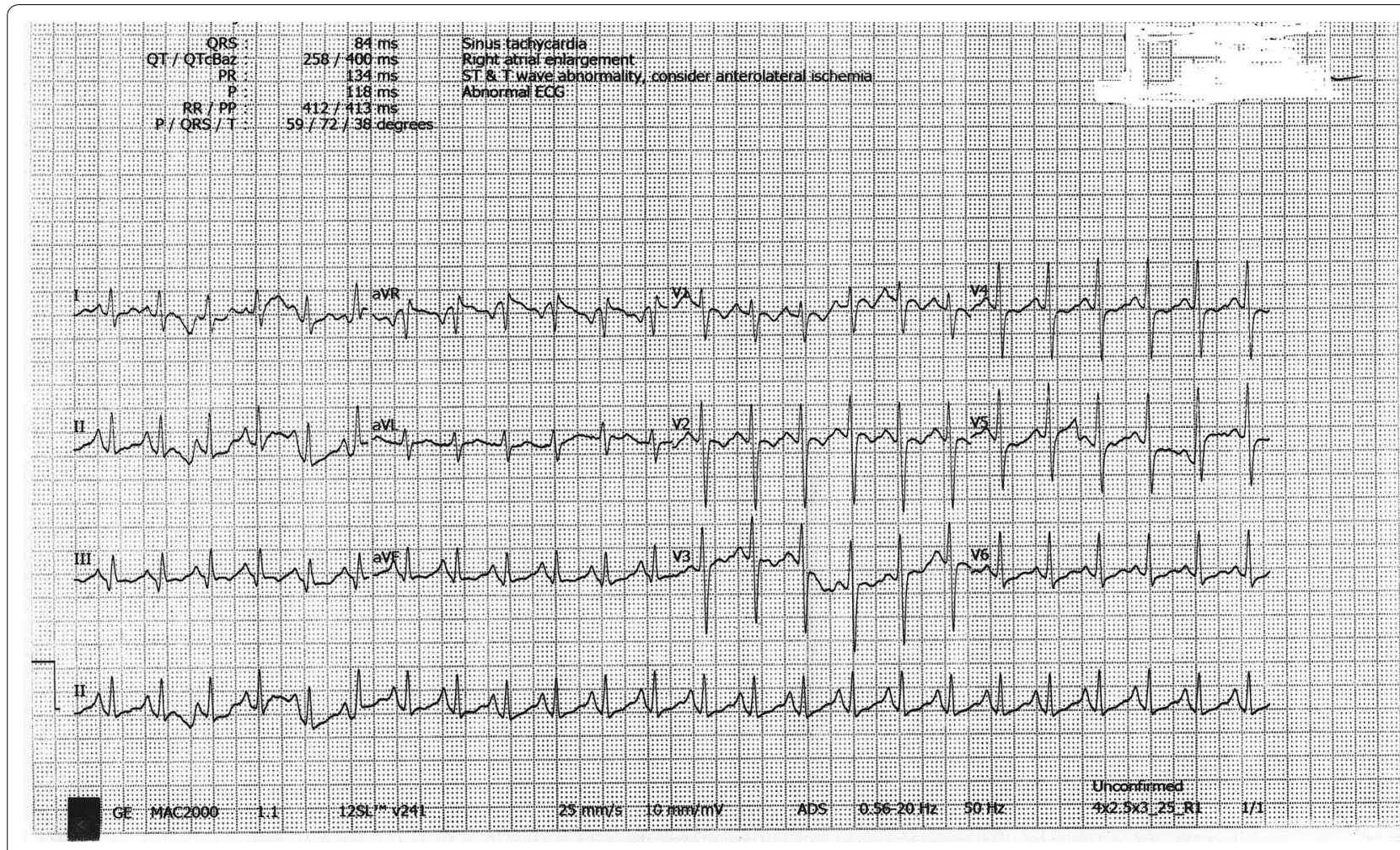

Fig. 3 On day 2, electrocardiography showed sinus tachycardia with ST/T wave abnormality in chest leads 
evaluated by a psychiatrist. On Day 4 , she was discharged with following heart rate 124/min with QRS duration in the limb lead $90 \mathrm{~ms}$ in ECG along with other normal vital signs.

\section{Discussion}

In Bangladesh, amitriptyline is a most commonly used drug among the tricyclic antidepressants. It is lipophilic and has a large volume of distribution. It is primarily metabolized by the liver. Most active metabolites of amitriptyline are nortriptyline and 10-hydroxynortriptyline [8]. In overdoses, amitriptyline exerts its effects [9-11] by the following way:

1. Inhibition of presynaptic neurotransmitter reuptake (norepinephrine and serotonin).

2. Blockade of the cardiac fast sodium channels.

3. Antagonism of central and peripheral muscarinic acetylcholine receptors.

4. Antagonism of peripheral alpha-1 adrenergic receptors.

5. Antagonism of histamine (H1) receptors.

6. Antagonism of central nervous system (CNS) gamma-aminobutyric acid (GABA)-A receptors.

7. Blocks the hERG human cardiac potassium channels.

In therapeutic doses, the elimination half-life of amitriptyline and its metabolites is $19-72 \mathrm{~h}$ [8]. In toxic doses, it is average $37 \mathrm{~h}$, and commonly greater than $60 \mathrm{~h}$ $[12,13]$ as pharmacokinetics differs from the therapeutic pharmacokinetics of amitriptyline in many ways [14]:

1. Due to anticholinergic effects, gut motility decreases. It delays the absorption of amitriptyline.

2. Metabolic pathways become saturated. It reduces the first pass metabolism resulting in increased bioavailability.

3. Overdoses cause respiratory depression resulting in acidaemia. It increases the amount the free drug due to effects on plasma glycoprotein binding.

4. Significant enterohepatic recirculation prolongs the final elimination.

Prolonged toxicity was also described in a CYP2D6deficient patient as CYP2D6 is responsible for the metabolism of amitriptyline and its metabolites metabolism [15].

In amitriptyline overdose, the progression of clinical toxicity is unpredictable. Acute ingestion of $>5 \mathrm{mg} / \mathrm{kg}$ causes significant cardiovascular, CNS and anticholinergic symptoms [16]. With it, the reported lowest dose of amitriptyline that causes severe toxicity in a young adult is $300 \mathrm{mg}$ [17].
Acute cardiovascular toxicity is primarily responsible for the mortality in amitriptyline overdose. Sinus tachycardia (rate $120-160$ beats/min in an adult) occurs due to inhibition of presynaptic norepinephrine reuptake and anticholinergic action [10]. Amitriptyline also inhibits the fast sodium channel in the His-Purkinje system and myocardial. As a result, depolarization of the cardiac action potential is slowed and propagation of depolarization though both myocardial and conducting tissue is delayed. Ultimately, it decreases conduction velocity, increases the duration of repolarization and prolongs absolute refractory period $[10,18]$. It also blocks the hERG human cardiac potassium channel which contributes to arrhythmogenic side effects of amitriptyline [11]. In ECG, prolongation of the PR, QRS and QT intervals, nonspecific ST-segment and T-wave changes, atrioventricular block, right axis deviation of the terminal $40 \mathrm{~ms}$ vector of the QRS complex in the frontal plane (T $40 \mathrm{~ms}$ axis) and the Brugada pattern (downsloping ST segment elevation in leads $\mathrm{V}_{1}-\mathrm{V}_{3}$ in association with right bundle branch block) is seen [19-23]. In several studies, several sensitive indicators are found to identify and risk-stratify the patients with cyclic antidepressant.

1. A T40-ms QRS axis between $120^{\circ}$ and $270^{\circ}$ : It is 8.6 times more common in TCA poisoning than that in non-TCA poisoning. In practical life, without specialized computer-assisted analysis, a T40-ms axis is not well quantified. An abnormal terminal rightward axis can be estimated by noting a negative deflection (terminal S wave) in lead I and aVL and a positive deflection (a terminal $\mathrm{R}$ wave) in lead aVR [24, 25].

2. The maximal limb leads QRS complex duration: QRS duration greater than $100 \mathrm{~ms}$ is associated with an increased incidence of serious toxicity, including coma, the need for intubation, hypotension, seizures and dysrhythmias [26].

3. Terminal $\mathrm{R}$ wave and $\mathrm{R} / \mathrm{S}$ ratio in aVR: The amplitude of terminal $\mathrm{R}$ wave in equal or more to $3 \mathrm{~mm}$ and $\mathrm{R} / \mathrm{S}$ equal or more to 0.7 in aVR are also sensitive in predicting seizures and dysrhythmias [26].

Fatal dysrhythmias are rare as ventricular tachycardia (VT) and ventricular fibrillation (VF) occur in only approximately $4 \%$ of all cases [6, 7]. It happens most often in patients with prolonged QRS complex duration and/or hypotension. Hypoxia, acidosis, hyperthermia, seizures and $\beta$-adrenergic agonist may also predispose to it [27].

Hypotension during an overdose occurs due to decreased contractility of the myocardium and peripheral vasodilatation due to antagonism of peripheral alpha-1 adrenergic receptors. Refractory hypotension during TCA overdose is the most common cause of death [28]. 
Altered mental status and seizures are the primary manifestations of CNS toxicity. Lethargy, alterations in consciousness, coma is the usual consequence. It is due to both antihistamine and anticholinergic effects, whereas seizure occurs as a result of antagonism of GABA-A receptor in the brain by TCA $[29,30]$. Some studies have indicated that the level of consciousness of presentation is the most sensitive clinical indicator of complications after a TCA overdose [20,31, 32].

In the management of a patient with AIVT, initially, the key issue is securing the airway, breathing, and circulation. After that, sodium bicarbonate should be used to treat the AIVT, even in the absence of acidosis before using any anti-arrhythmic drugs. To assess the use of sodium bicarbonate in AIVT, several studies were done [33-35]. One guideline recommends it for the treatment of AIVT [36]. The use of sodium bicarbonate in AIVT gives some benefit [33, 37-39].

1. It provides high sodium load for greater sodium entry into the myocardial cells in the presence of sodium channel blockade by the amitriptyline.

2. It alkalinizes the blood resulting in reduction of efficacy of the amitriptyline for the sodium channel leading to reduction of TCA binding to sodium channel.

3. Alkalization of the blood reduces the unbound amitriptyline and increases the protein binding. It ultimately serves to counteract sodium channel blockade in the myocardium by amitriptyline.

4. Alkalization of the blood also prevents acidosis, which exacerbates the cardiac toxicity.

5. The sodium and the bicarbonate both act synergistically to increase their individual effects.

The initial dosage is $1-2 \mathrm{mEq} / \mathrm{kg}$ IV bolus in AIVT [34, $35,40]$. There is no specific recommendation about the timing of repeat dose. It is wiser to wait at least $10 \mathrm{~min}$. In this case, AIVT reverted within $10 \mathrm{~min}$ of the 1 st dose of sodium bicarbonate. After that, a continuous IV infusion of sodium bicarbonate will be started to maintain a blood pH 7.50-7.55 [41]. It is better to taper the bicarbonate therapy before discontinuing it after the clinical improvement of conscious level and improvement, but not necessarily normalization of abnormal ECG findings. In the meantime, the clinical and lab parameters should be monitored closely as volume overload, hypokalemia, hypernatremia, and metabolic alkalosis resulted from prolonged sodium bicarbonate therapy [42-44]. ECG finding as sinus tachycardia may persist for up to 1 week following ingestions [45].

Treatment with magnesium sulphate may be considered in AIVT. Several studies are, however, done to assess its value in the treatment of AIVT [46-48]. One randomized controlled trial recruited a total of 72 patients with TCA overdose examining the efficacy of magnesium sulphate on patients of TCA overdose in mean duration of hospital stay and mortality rates between the group treated with bicarbonate infusion only and the group treated with bicarbonate infusion plus infusion of magnesium sulphate revealed that reduced hospital stays $(\mathrm{p}<0.001)$ and reduced mortality rate $(\mathrm{p}=0.052)$ observed in group treated with infusion of bicarbonate plus magnesium sulphate [49]. One guideline recommends the usage of magnesium sulphate in cases of refractory dysrhythmias causing hemodynamic instability [36].

Anti-arrhythmic agents-Class IA (quinidine, procainamide, disopyramide), Class IC (flecainide, propafenone) and Class III (amiodarone, sotalol) are contraindicated as Class IA, IC prolongs the depolarization like amitriptyline and Class III prolongs the QT interval, which predisposes to develop arrhythmias [10].

Though the use of intravenous lipid emulsion (ILE) in the treatment of toxicity of lipophilic drug overdose is limited to a few case reports and one randomized controlled trial. Realizing the benefit outweighs the hazard it was used in this instance when the patients' point of consciousness did not improve after $24 \mathrm{~h}$ of sodium bicarbonate infusion. The precise mechanism of ILE is not fully realized. The original theory is well-known as "lipid-sink"; nowadays it is supplanted with the more exact term "lipid shuttle" mechanism as it exercises its effects by three mechanisms-(1) lipid scavenging of the drugs (2) a volume effect (3) the cardiotonic effects. It is found in a study of combining dose-response to the effects of ILE in bupivacaine-poisoned rats with PBPK/ PD modeling [50-53]. In an amitriptyline overdose or poisoning, probably ILE acts in like style as both amitriptyline \& bupivacaine has a similar pharmacological weak base peak 9.4 capable of accepting a proton to become cationic [54]. In this example, bicarbonate infusion before ILE administration may increase the percentage of circulating amitriptyline in an unionized state and augment the efficacy of the 'lipid-shuttle' as in acidosis, bupivacaine demonstrated a lower bupivacainelipid binding capacity $[55,56]$. As far we know, in all case reports of amitriptyline overdose treated with ILE, sodium bicarbonate was infused concomitantly with ILE. The outcome was good [57-65]. Probably bicarbonate-induced alkalosis may increase amitriptyline-lipid binding capacity in whole instances. One randomized control trial included a total of 108 cases examining the efficacy of ILE on duration of cardiotoxicity and subsequent complications of severe TCA showed that there is no statistically significant difference was observed 
between the groups received standard treatment with sodium bicarbonate and standard treatment plus intravenous lipid emulsion concerning the time needed for ECG reversal, in blood pressure at the time of ECG reversal, in mortality and in length of hospitalization. Though it also noted that time needs for ECG reversal 20 min shorter in the ILE group. The complete article is still not put out and not assessed to check the quality of evidence [66]. To determine the role of acid/base status on the potential efficacy of ILE therapy on amitriptyline overdose, more work is needed. Though the causal relation to ILE infusion is not clear, reports of complications in adults are transient lipemia, pancreatitis, acute respiratory distress syndrome (ARDS) and post-ILE cardiac arrest. Recently the clinical toxicology's lipid emulsion collaborative work group said that the quality of evidence is low to very low, but they didn't remark on 'not the use of ILE in amitriptyline overdose' [67].

After being reverse the dysrhythmias, is there any role of plasmapheresis, hemodialysis, and hemoperfusion? Recently, EXTRIP Workgroup recommended not to performing extracorporeal treatment (ECTR) in patients with TCA poisoning [68]. Even afterward the utilization of high-cut off $(\mathrm{HCO})$ dialyzer, the eliminated amount did not surpass $3 \%$ of the total ingested dose per dialysis session reported in one case report [69].

In TCA overdose, all major complications occur within $6 \mathrm{~h}$ of ingestion [70]. Though the incidence of late complication is really low, ventricular arrhythmias had been reported up to 5 days after ingestion [71-73]. All patients should receive cardiac monitoring until the ECG has become normal. An alert and orientated patient with QRS duration less than $100 \mathrm{~ms}$ in the ECG is the best indicator for safe transfer to a medical or psychiatric ward for psychiatric evaluation and discharge after gastrointestinal (GI) decontamination and a minimum observation of $6 \mathrm{~h}[32,74]$.

\section{Conclusions}

AIVT is one of the devastating complications of an amitriptyline overdose. Sometimes, diagnosis of AIVT is very hard as there is no history of an overdose obtained due to an altered story of awareness. Diagnosis should be performed along the foundation of clinical grounds and classic ECG changes. Anti-arrhythmic drugs should be warded off in this example. Thus, wise use of medication may save a life.

\footnotetext{
Abbreviations

AIVT: amitriptyline-induced ventricular tachycardia; ARDS: acute respiratory distress syndrome; CCU: cardiac coronary unit; CNS: central nervous system; ECG: electrocardiography; ECTR: extracorporal treatment; Gl: gastrointestinal; HCO: high-cut off; HP: hemoperfusion; ILE: intravenous lipid emulsion; TCA: tricyclic antidepressant; $\mathrm{VT}$ : ventricular tachycardia; VF: ventricular fibrillation.
}

\section{Authors' contributions}

KMNS is the first author. He was involved in the diagnosis and management of the case. He also wrote a part of the manuscript. MSI mainly involved in reviewing the previous literature and writing the manuscript. AWC provided us overall support. BPS and SRK managed the patient. SK wrote and edited the manuscript. All authors read and approved the final manuscript.

\section{Author details}

${ }^{1}$ Dhaka Medical College Hospital, Dhaka, Bangladesh. ${ }^{2}$ Anwer Khan Modern Medical College Hospital, Road-08, Dhanmondi, Dhaka 1209, Bangladesh. ${ }^{3}$ Dr. Sirajul Islam Medical College \& Hospital Ltd, Dhaka, Bangladesh.

\section{Acknowledgements}

Not applicable.

\section{Competing interests}

The authors declare that they have no competing interests.

\section{Availability of data and materials}

The data that support the findings of this study are available from Record File Section, Dhaka Medical College Hospital but restrictions apply to the availability of these data, which were used under license for this case report, and so are not publicly available. Data are however available from the authors upon reasonable request and with permission of the authority.

\section{Consent for publication}

A written informed consent was obtained from the patient for publication of this Case Report and any accompanying images.

\section{Funding}

None of the authors have received any grant from any funding agency in the public, commercial, or not-for-profit sectors.

\section{Publisher's Note}

Springer Nature remains neutral with regard to jurisdictional claims in published maps and institutional affiliations.

Received: 3 November 2016 Accepted: 8 July 2017

Published online: 14 July 2017

\section{References}

1. Lancaster NP, Foster AR. Suicidal attempt by imipramine over-dosage. $\mathrm{Br}$ Med J. 1959;2(5164):1458.

2. Henry JA, Alexander CA, Sener EK. Relative mortality from overdose of antidepressants. BMJ. 1995;310(6974):221-4.

3. Henry DJ. A fatal toxicity index for antidepressant poisoning. Acta Psychiatr Scand. 1989;80(S354):37-45.

4. Farmer RD, Pinder RM. Why do fatal overdose rates vary between antidepressants? Acta Psychiatr Scand. 1989;80(S354):25-35.

5. Buckley NA, Dawson AH, White IM, Henry DA. Greater toxicity in overdose of dothiepin than of other tricyclic antidepressants. Lancet. 1994;343(8890):159-62.

6. Pentel P, Sioris L. Incidence of late arrhythmias following tricyclic antidepressant overdose. J Clin Toxicol. 1981;18(5):543-8.

7. Goldberg RJ, Capone RJ, Hunt JD. Cardiac complications following tricyclic antidepressant overdose: issues for monitoring policy. JAMA. 1985;254(13):1772-5.

8. Ereshefsky L, Tran-Johnson T, Davis CM, LeRoy A. Pharmacokinetic factors affecting antidepressant drug clearance and clinical effect: evaluation of doxepin and imipramine - new data and review. Clin Chem. 1988;34(5):863-80.

9. Franssen EJ, Kunst PW, Bet PM, van Schijndel RS, Van Loenen AC, Wilhelm AJ. Toxicokinetics of nortriptyline and amitriptyline: two case reports. Ther Drug Monit. 2003;25(2):248-51.

10. Kerr GW, McGuffie AC, Wilkie S. Tricyclic antidepressant overdose: a review. Emerg Med J. 2001;18(4):236-41. 
11. Jo SH, Youm JB, Lee CO, Earm YE, Ho WK. Blockade of the HERG human cardiac K+ channel by the antidepressant drug amitriptyline. Br J Pharmacol. 2000;129(7):1474-80.

12. Swartz CM, Sherman A. The treatment of tricyclic antidepressant overdose with repeated charcoal. J Clin Psychopharmacol. 1984;4(6):336-40.

13. Hultén BÅ, Heath A, Knudsen K, Nyberg G, Svensson C, Mårtensson E. Amitriptyline and amitriptyline metabolites in blood and cerebrospinal fluid following human overdose. J Toxicol Clin Toxicol. 1992;30(2):181-201.

14. Jarvis MR. Clinical pharmacokinetics of tricyclic antidepressant overdose. Psychopharmacol Bull. 1990;27(4):541-50.

15. Smith JC, Curry SC. Prolonged toxicity after amitriptyline overdose in a patient deficient in CYP2D6 activity. J Med Toxicol. 2011;7(3):220-3.

16. Woolf AD, Erdman AR, Nelson LS, Caravati EM, Cobaugh DJ, Booze LL, Wax PM, Manoguerra AS, Scharman EJ, Olson KR, Chyka PA. Tricyclic antidepressant poisoning: an evidence-based consensus guideline for out-of-hospital management. Clin Toxicol. 2007;45(3):203-33.

17. Chamsi-Pasha H, Barnes PC. Myocardial infarction: a complication of amitriptyline overdose. Postgrad Med J. 1988;64(758):968-70.

18. Glassman AH. Cardiovascular effects of tricyclic antidepressants. Annu Rev Med. 1984;35(1):503-11.

19. Shannon MW. Duration of QRS disturbances after severe tricyclic antidepressant intoxication. J Toxicol Clin Toxicol. 1992;30(3):377-86.

20. Thanacoody HR, Thomas SH. Tricyclic antidepressant poisoning. Toxicol Rev. 2005;24(3):205-14.

21. Marshall JB, Forker AD. Cardiovascular effects of tricyclic antidepressant drugs: therapeutic usage, overdose, and management of complications. Am Heart J. 1982;103(3):401-14.

22. Christensen $\mathrm{P}$, Thomsen HY, Pedersen OL, Thayssen $\mathrm{P}, \mathrm{Oxh} \varnothing \mathrm{j} \mathrm{H}$ Kragh-Sørensen P, Gram LF. Cardiovascular effects of amitriptyline in the treatment of elderly depressed patients. Psychopharmacology. 1985;87(2):212-5.

23. Burgess CD, Montgomery S, Wadsworth J, Turner P. Cardiovascular effects of amitriptyline, mianserin, zimelidine and nomifensine in depressed patients. Postgrad Med J. 1979;55(648):704-8.

24. Niemann JT, Bessen HA, Rothstein RJ, Laks MM. Electrocardiographic criteria for tricyclic antidepressant cardiotoxicity. Am J Cardiol. 1986;57(13):1154-9.

25. Wolfe TR, Caravati EM, Rollins DE. Terminal 40-ms frontal plane QRS axis as a marker for tricyclic antidepressant overdose. Ann Emerg Med. 1989;18(4):348-51.

26. Liebelt EL, Francis PD, Woolf AD. ECG lead aVR versus QRS interval in predicting seizures and arrhythmias in acute tricyclic antidepressant toxicity. Ann Emerg Med. 1995;26(2):195-201.

27. Taboulet P, Michard F, Muszynski J, Galliot-Guilley M, Bismuth C. Cardiovascular repercussions of seizures during cyclic antidepressant poisoning. J Toxicol Clin Toxicol. 1995;33(3):205-11.

28. Strøm J, Madsen PS, Nielsen NN, Sørensen MB. Acute self-poisoning with tricyclic antidepressants in 295 consecutive patients treated in an ICU. Acta Anaesthesiol Scand. 1984;28(6):666-70.

29. Olson KR, Kearney TE, Dyer JE, Benowitz NL, Blanc PD. Seizures associated with poisoning and drug overdose. Am J Emerg Med. 1994;12(3):392-5.

30. Citak A, Soysal DD, Uecsel R, Karaboecueoglu M, Uzel N. Seizures associated with poisoning in children: tricyclic antidepressant intoxication. Pediatr Int. 2006;48(6):582-5.

31. Emerman CL, Connors AF, Burma GM. Level of consciousness as a predictor of complications following tricyclic overdose. Ann Emerg Med. 1987;16(3):326-30.

32. Hultén BÅ, Adams R, Askenasi R, Dallos V, Dawling S, Volans G, Heath A. Predicting severity of tricyclic antidepressant overdose. J Toxicol Clin Toxicol. 1992;30(2):161-70.

33. Brown TC, Barker GA, Dunlop ME, Loughnan PM. The use of sodium bicarbonate in the treatment of tricyclic antidepressant-induced arrhythmias. Anaesth Intensive Care. 1973;1(3):203-10.

34. Sasyniuk BI, Jhamandas V, Valois M. Experimental amitriptyline intoxication: treatment of cardiac toxicity with sodium bicarbonate. Ann Emerg Med. 1986;15(9):1052-9.

35. Blackman K, Brown SG, Wilkes GJ. Plasma alkalinization for tricyclic antidepressant toxicity: a systematic review. Emerg Med. 2001;13(2):204-10.
36. Body R, Bartram T, Azam F, Mackway-Jones K. Guidelines in Emergency Medicine Network (GEMNet): guideline for the management of tricyclic antidepressant overdose. Emerg Med J. 2011;28(4):347-68.

37. Bruccoleri RE, Burns MM. A literature review of the use of sodium bicarbonate for the treatment of QRS widening. J Med Toxicol. 2016;12(1):121-9.

38. Sasyniuk $\mathrm{Bl}$, Jhamandas V. Mechanism of reversal of toxic effects of amitriptyline on cardiac purkinje fibers by sodium bicarbonate. J Pharmacol Exp Ther. 1984;231(2):387-94.

39. Levitt MA, Sullivan JB, Owens SM, Burnham L, Finley PR. Amitriptyline plasma protein binding: effect of plasma $\mathrm{pH}$ and relevance to clinical overdose. Am J Emerg Med. 1986;4(2):121-5.

40. Shannon M, Merola J, Lovejoy FH. Hypotension in severe tricyclic antidepressant overdose. Am J Emerg Med. 1988;6(5):439-42.

41. Hoffman JR, Votey SR, Bayer M, Silver L. Effect of hypertonic sodium bicarbonate in the treatment of moderate-to-severe cyclic antidepressant overdose. Am J Emerg Med. 1993;11(4):336-41.

42. Zuckerman GB, Conway EE. Pulmonary complications following tricyclic antidepressant overdose in an adolescent. Ann Pharmacother. 1993;27(5):572-4.

43. Wrenn K, Smith BA, Slovis CM. Profound alkalemia during treatment of tricyclic antidepressant overdose: a potential hazard of combined hyperventilation and intravenous bicarbonate. Am J Emerg Med. 1992;10(6):553-5.

44. Guharoy SR. Adult respiratory distress syndrome associated with amitriptyline overdose. Vet Hum Toxicol. 1994;36(4):316-7.

45. Serafimovski N, Thorball N, Asmussen I, Lunding M. Tricyclic antidepressive poisoning with special reference to cardiac complications. Acta Anaesthesiol Scand. 1975;19(s57):55-63.

46. Knudsen K, Abrahamsson J. Magnesium sulphate in the treatment of ventricular fibrillation in amitriptyline poisoning. Eur Heart J. 1997; 18(5):881-2.

47. Sarisoy O, Babaoglu K, Tugay S, Barn E, Gokalp AS. Efficacy of magnesium sulfate for treatment of ventricular tachycardia in amitriptyline intoxication. Pediatr Emerg Care. 2007;23(9):646-8.

48. Knudsen K, Abrahamsson J. Effects of magnesium sulfate and lidocaine in the treatment of ventricular arrhythmias in experimental amitriptyline poisoning in the rat. Criti Care Med. 1994;22(3):494-8.

49. Emamhadi M, Mostafazadeh B, Hassanijirdehi M. Tricyclic antidepressant poisoning treated by magnesium sulfate: a randomized, clinical trial. Drug Chemical Toxicol. 2012;35(3):300-3.

50. Eisenkraft A, Falk A. The possible role of intravenous lipid emulsion in the treatment of chemical warfare agent poisoning. Toxicol Rep. 2016:3:202-10

51. Fettiplace MR, Akpa BS, Ripper R, Zider B, Lang J, Rubinstein I, Weinberg $\mathrm{G}$. Resuscitation with lipid emulsion dose-dependent recovery from cardiac pharmacotoxicity requires a cardiotonic effect. Anesthesiology. 2014;120(4):915-25.

52. Fettiplace MR, Weinberg G. Past, present, and future of lipid resuscitation therapy. J Parenter Enteral Nutr. 2015;39(Suppl 1):72S-83S.

53. Weinberg GL. Lipid emulsion infusion resuscitation for local anesthetic and other drug overdose. Anesthesiology. 2012;117(1):180-7.

54. Harvey M, Cave G. Case report: successful lipid resuscitation in multi-drug overdose with predominant tricyclic antidepressant toxidrome. Int J Emerg Med. 2012;5(1):1.

55. Mazoit JX, Le Guen R, Beloeil H, Benhamou D. Binding of longlasting local anesthetics to lipid emulsions. J Am Soc Anesthesiol. 2009;110(2):380-6.

56. Strichartz GR, Sanchez V, Arthur GR, Chafetz R, Martiny D. Fundamental properties of local anesthetics. II. Measured octanol: buffer partition coefficients and pKa values of clinically used drugs. Anesth Analg. 1990;71(2):158-70.

57. Agarwala R, Ahmed SZ, Wiegand TJ. Massive TCA ingestion treated successfully with a prolonged infusion of $20 \%$ lipid emulsion. Clin Toxicol. 2012;50(7):579

58. Engels PT, Davidow JS. Intravenous fat emulsion to reverse haemodynamic instability from intentional amitriptyline overdose. Resuscitation. 2010;81(8):1037-9.

59. Harvey M, Cave G. Case report: successful lipid resuscitation in multi-drug overdose with predominant tricyclic antidepressant toxidrome. Int J Emerg Med. 2012;5(1):1. 
60. Hellig J, Von Watzdorf I, Lahri S, Vallabh K, Allgaier RL. Chewing the fat: a case report on intravenous lipid emulsion to reverse cardiotoxicity from intentional amitriptyline overdose. Afr J Emerg Med. 2012;2(4):159-62.

61. Hendron D, Menagh G, Sandilands EA, Scullion D. Tricyclic antidepressant overdose in a toddler treated with intravenous lipid emulsion. Pediatrics. 2011;128(6):e1628-32.

62. Huge V, Baschnegger H, Moehnle P, Peraud A, Briegel J. Amitriptylineinduced cardiac arrest: treatment with fat emulsion. Anaesthesist. 2011;60(6):541-5.

63. Kiberd MB, Minor SF. Lipid therapy for the treatment of a refractory amitriptyline overdose. CJEM. 2012;14(03):193-7.

64. Levine M, Brooks DE, Franken A, Graham R. Delayed-onset seizure and cardiac arrest after amitriptyline overdose, treated with intravenous lipid emulsion therapy. Pediatrics. 2012;130(2):e432-8.

65. Nair A, Paul FK, Protopapas M. Management of near fatal mixed tricyclic antidepressant and selective serotonin reuptake inhibitor overdose with Intralipid [R] 20\% emulsion. Anaesth Intensive Care. 2013;41(2):264-6.

66. Kasnavieh FH, Kasnavier MH, Noddoushan SJ, et al. Intravenous lipid emulsion for the treatment of tricyclic antidepressant toxicity: a randomized controlled trial. VIIth Mediterranean Emergency Medicine Congress 8-11 Sept 2013; Marseille, France; 2013.
67. Levine M, Hoffman RS, Lavergne V, Stork CM, Graudins A, Chuang R, Stellpflug SJ, Morris M, Miller-Nesbitt A, Gosselin S. Systematic review of the effect of intravenous lipid emulsion therapy for non-local anesthetics toxicity. Clin Toxicol. 2016;54(3):194-221.

68. Yates C, Galvao T, Sowinski KM, Mardini K, Botnaru T, Gosselin S, Hoffman RS, Nolin TD, Lavergne V, Ghannoum M. Extracorporeal treatment for tricyclic antidepressant poisoning: recommendations from the EXTRIP Workgroup. Semin Dial. 2014;27(4):381-9.

69. Schmidt JJ, Bertram A, Kühn-Velten WN, Suhling H, Wiesner O, Schneider A, Kielstein JT. Treatment of amitriptyline intoxications by extended high cut-off dialysis. Clin kidney J. 2015;8(6):796-9.

70. Tokarski GF, Young MJ. Criteria for admitting patients with tricyclic antidepressant overdose. J Emerg Med. 1988;6(2):121-4.

71. Pentel P, Sioris L. Incidence of late arrhythmias following tricyclic antidepressant overdose. Clin Toxicol. 1981;18(5):543-8.

72. Barnes RJ, Kong SM, Wu RW. Electrocardiographic changes in amitriptyline poisoning. Br Med J. 1968;3(5612):222-3.

73. Freeman JW, Mundy GR, Beattie RR, Ryan C. Cardiac abnormalities in poisoning with tricyclic antidepressants. Br Med J. 1969;2(5657):610-1.

74. Callaham M. Epidemiology of fatal tricyclic antidepressant ingestion: implications for management. Ann Emerg Med. 1985;14(1):1-9.

\section{Submit your next manuscript to BioMed Central and we will help you at every step:}

- We accept pre-submission inquiries

- Our selector tool helps you to find the most relevant journal

- We provide round the clock customer support

- Convenient online submission

- Thorough peer review

- Inclusion in PubMed and all major indexing services

- Maximum visibility for your research

Submit your manuscript at www.biomedcentral.com/submit 